\title{
EFFECT OF ALENDRONATE ON THE HEALING TIME OF DISTAL RADIAL FRACTURES TREATED CONSERVATIVELY: AN OBSERVATIONAL STUDY
}

\author{
NIDHIN KOSHY, DEEPAK PINTO, PREMJIT SUJIR*, VARGHESE JOE, GHANASHYAM KAMATH K (DECEASED)
}

Department of Orthopaedics, Kasturba Medical College, Mangalore, Karnataka, India. Email: premjit78@gmail.com

Received: 26 February 2017, Revised and Accepted: 21 July 2017

\begin{abstract}
Objective: Although fragility fractures of the distal radius are common, osteoporosis treatment requires exploration as attempts to improve postfracture investigations have been only partially successful. Bisphosphonates may help minimize the risk of secondary fractures but being a potent antiresorptive agent; it raises concerns about adverse effects on the healing process. This observational study examines the effect of bisphosphonate (alendronate) on healing of acute fractures of distal radius through 66 patients aged $>45$ years admitted to two tertiary care hospitals in Mangalore from May 2014 to September 2016.
\end{abstract}

Methods: The methodology consists of purposive sampling from two groups: Control having 33 patients not on alendronate therapy and cases comprising 33 who are on alendronate as part of prophylaxis for osteoporosis before fracture occurrence, with outpatient reviews at 2-week intervals starting from the $6^{\text {th }}$ till fracture union seen. At each visit, plain radiographs of the involved wrist were taken to yield time to cortical bridging, with range of active movement of the affected wrist taken using a goniometer. Data were analyzed using Statistical Package for the Social Sciences software version 17.0 for t values, $\mathrm{p}$ values and correlations and results were presented in the form of graphs and tables.

Results: No significant differences were observed in the groups (as per p values) w.r.t. gender (0.804), age (0.835), time to healing (1.000), dorsiflexion (0.956), palmar flexion (0.670), ulnar deviation (0.441), radial deviation (1.000), supination (0.132), or pronation (0.302). Quick Disabilities of the Arm, Shoulder and Hand score did not differ by $>95 \%$ between the groups over the analysis period.

Conclusion: It was observed that alendronate administration in distal radius fractures did not appear to delay fracture healing times radiologically or clinically.

Keywords: Fragility fracture, Osteoporosis, Distal radius, Bisphosphonate, Alendronate.

(C) 2017 The Authors. Published by Innovare Academic Sciences Pvt Ltd. This is an open access article under the CC BY license (http://creativecommons. org/licenses/by/4. 0/) DOI: http://dx.doi.org/10.22159/ajpcr.2017.v10i11.18156

\section{INTRODUCTION}

Although fragility fractures of the distal radius are common mostly in women in their 60 s or 70 s [1], treatment for osteoporosis after such fractures requires in-depth exploration. These fractures are seen to occur at a younger age in patients in comparison with other major osteoporotic fractures [2] and are the most common fractures to occur in the postmenopausal period [3]. Treatments targeted at improving postfracture investigations of osteoporosis have only been partially successful [4].

Treatment using bisphosphonates following a fracture could help in minimizing the risk of a secondary fracture [5]. However, the possibilities of adverse effects of these drugs on the healing process of fractures due to them being antiresorptive agents must always be considered [6]. Tests have been performed on both animals as well as humans in different studies to understand the interaction between bisphosphonates and the fracture healing process. Animal studies have indicated that inhibition of the hard callus remodeling to mature lamella bone occurs as a consequence of bisphosphonates $[7,8]$. However, studies on humans, in the same manner, have not led to definitive results [9].

The objective of this study is to "examine the effect of bisphosphonate (alendronate) on the healing of acute fractures of the distal radius." The study population consisted of 66 patients aged 45 years and above, who were admitted to the Government Wenlock Hospital and the Kasturba Medical College (KMC) Hospital in Attavar, Mangalore, from May 2014 to September 2016.

The scope of the study extends to determining the level to which administration of alendronate on patients has changed the way that their fractures have healed with reference to those who were not on the alendronate therapy, by examining time of healing, and functional evaluation through Quick Disabilities of the Arm, Shoulder and Hand (QuickDASH) scores.

\section{METHODS}

A total of 66 patients aged 45 years and above with acute fragility fractures of the distal radius who presented themselves to the outpatient department of the Government Wenlock Hospital and KMC, Mangalore, from the period dating from May 2014 to September 2016, were considered for this study. 38 patients were excluded from the study based on exclusion criteria and noncompliance with regular follow-up. Group allocation was carried out based on the patients visit to the hospital, with cases and controls alternating with each other. It was found that patients who did not take prophylaxis outweighed patients who did. Hence, once each case was selected, every other patient who satisfied as a control was discarded from the study until a patient who met the criteria for a case was enrolled. 127 patients who met the criteria for control were thereby discarded in the process. The study has been done in compliance with and on approval from the Institutional Ethics Committee, KMC, Mangalore.

Patients with associated fracture of the ulnar styloid were not excluded from the study. Patients with rheumatoid arthritis, chronic renal disease, dementia, open fractures, associated neurovascular complications identified at the time of enrollment, fractures with significant bone loss requiring bone graft or other graft materials, a concomitant fracture of metaphysis of distal ulna and comminuted fractures were excluded from this study. 
Fractures were reduced manually under a hematoma block and visualized under image intensifier or using a radiograph. Those fractures which did not achieve reduction were taken up for surgical procedures and therefore excluded from the study. The fracture patterns were classified based on AO system.

Patients were made to complete the QuickDASH questionnaire to evaluate preinjury status. The QuickDASH is a validated 11-item questionnaire for the evaluation of upper extremity symptoms and function. Along with the QuickDASH questionnaire, the patients were required to fill a consent form for enrolment into the study along with details of age, sex, and hospital registration number. Patients were given follow-up dates 6 weeks after the first visit. When a patient arrived for the first follow-up visit at 6 weeks, plain anteroposterior (AP) and lateral view radiographs of the involved wrist were taken after removal of plaster cast after which cortical bridging was assessed at the fracture site. Fractures were deemed healed if at least 3 out of 4 cortices were found to be united. If union was not found in the first follow-up visit, they were asked to be available for review at 2-week intervals till union was noticed. At each visit along with plain radiographs, range of active movements (flexion, extension, supination, pronation, radial, and ulnar deviation) were measured with the assistance of a goniometer.

The following parameters were measured for each examined patient.

i. Time of healing (weeks): Time taken from the day of fracture reduction to the establishment of cortical bridging across the fracture fragments assessed from AP and lateral radiographs (union of 3 out of 4 cortices)

ii. QuickDASH score: Questionnaire which helps to determine preinjury status (detailed in the previous section)

iii. Dorsi flexion: Backward flexion of the hand [10]

iv. Palmar flexion: Bending the hand toward the palmar surface [10]

v. Ulnar deviation: Movement of the hand toward the ulnar side of the forearm [10]

vi. Radial deviation: Movement of the hand toward the radial side of the forearm [10]

vii. Supination: Turning the palm forward (anteriorly) or upward which is performed by lateral rotation of the forearm [10]

viii. Pronation: Turning the palm backward (posteriorly) which is performed by medial rotation of the forearm [10].

\section{RESULTS}

The primary outcome was the process of healing assessed radiologically by the observer. Other parameters were the range of movements of the wrist joint and the functional restriction as assessed by QuickDASH.

The following statistics were used for each of the above parameters to understand the statistical significance of each of them: Mean, standard deviation, $t$ - and p-values as well as the Pearson's correlation coefficient. From Table 1, it can be inferred that all parameters are seen to have a statistical significance which is $<95 \%$ when looking at the cases and controls groups which are below the required range as per this study.

These results show that there is not a significant difference between patients who were being administered alendronate, to those who were not on the treatment, as demonstrated by their high $\mathrm{p}>0.05$.

Graphs 1 and 2 shows the arithmetic mean of both the groups as well as for the total set for QuickDASH score as well as for the time of healing (weeks).

When looking at the correlations between parameters, the following results were seen as shown in Tables 2 and 3, which have been obtained from the software.

On close examination of the correlation values presented above, it can be seen that QuickDASH score correlates negatively with all other parameters in both cases and controls groupings. Time of healing correlates positively with all wrist movements and negatively with
Table 1: Statistical derivations for cases, controls, and total groupings

\begin{tabular}{|c|c|c|c|c|c|}
\hline Parameter & Group & $\mathbf{N}$ & Mean \pm SD & t-value & $p$ value \\
\hline \multirow[t]{3}{*}{ Gender } & Cases & 33 & - & 0.062 & 0.804 \\
\hline & Controls & 33 & & & \\
\hline & Total & 66 & & & \\
\hline \multirow[t]{3}{*}{ Age } & Cases & 33 & $63.70 \pm 10.054$ & 0.210 & $0.835 \mathrm{NS}$ \\
\hline & Controls & 33 & $64.24 \pm 11.068$ & & \\
\hline & Total & 66 & $63.97 \pm 10.495$ & & \\
\hline \multirow{3}{*}{$\begin{array}{l}\text { QuickDASH } \\
\text { score }\end{array}$} & Cases & 33 & $25.22 \pm 7.639$ & 1.809 & $0.075 \mathrm{NS}$ \\
\hline & Controls & 33 & $28.79 \pm 8.367$ & & \\
\hline & Total & 66 & $27.01 \pm 8.150$ & & \\
\hline \multirow{3}{*}{$\begin{array}{l}\text { Time of } \\
\text { healing } \\
\text { (weeks) }\end{array}$} & Cases & 33 & $7.27 \pm 1.790$ & 0.000 & $1.000 \mathrm{NS}$ \\
\hline & Controls & 33 & $7.27 \pm 1.989$ & & \\
\hline & Total & 66 & $7.27 \pm 1.877$ & & \\
\hline \multirow[t]{3}{*}{ Dorsi flexion } & Cases & 33 & $49.09 \pm 11.555$ & 0.055 & $0.956 \mathrm{NS}$ \\
\hline & Controls & 33 & $48.94 \pm 10.662$ & & \\
\hline & Total & 66 & $49.02 \pm 11.032$ & & \\
\hline Palmar & Cases & 33 & $60.00 \pm 12.374$ & 0.428 & $0.670 \mathrm{NS}$ \\
\hline \multirow[t]{2}{*}{ flexion } & Controls & 33 & $58.79 \pm 10.535$ & & \\
\hline & Total & 66 & $59.39 \pm 11.419$ & & \\
\hline Ulnar & Cases & 33 & $20.61 \pm 6.344$ & 0.776 & $0.441 \mathrm{NS}$ \\
\hline \multirow[t]{2}{*}{ deviation } & Controls & 33 & $19.39 \pm 6.344$ & & \\
\hline & Total & 66 & $20.00 \pm 6.325$ & & \\
\hline Radial & Cases & 33 & $12.27 \pm 5.741$ & 0.000 & $1.000 \mathrm{NS}$ \\
\hline \multirow[t]{2}{*}{ deviation } & Controls & 33 & $12.27 \pm 5.168$ & & \\
\hline & Total & 66 & $12.27 \pm 5.419$ & & \\
\hline \multirow[t]{3}{*}{ Supination } & Cases & 33 & $58.64 \pm 12.328$ & 1.525 & $0.132 \mathrm{NS}$ \\
\hline & Controls & 33 & $54.09 \pm 11.888$ & & \\
\hline & Total & 66 & $56.36 \pm 12.233$ & & \\
\hline \multirow[t]{3}{*}{ Pronation } & Cases & 33 & $45.61 \pm 12.976$ & 1.040 & $0.302 \mathrm{NS}$ \\
\hline & Controls & 33 & $42.47 \pm 13.056$ & & \\
\hline & Total & 66 & $43.94 \pm 13.024$ & & \\
\hline
\end{tabular}

DASH: Disabilities of the Arm, Shoulder and Hand

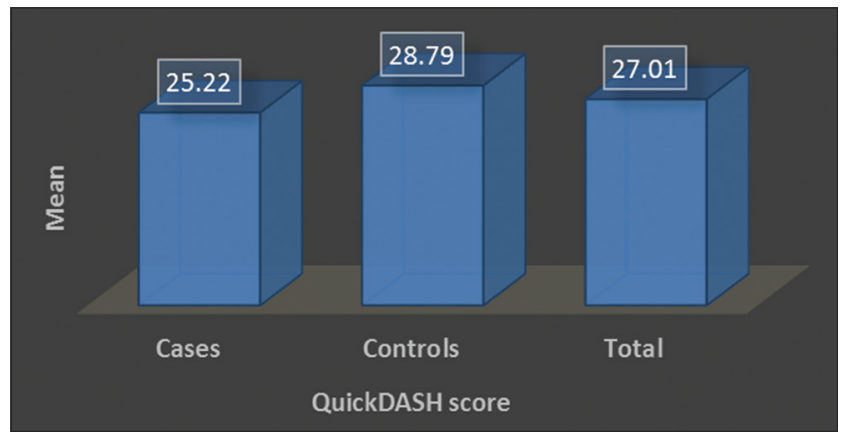

Graph 1: Mean of groups and total for Quick Disabilities of the Arm, Shoulder and Hand score

QuickDASH score in cases group, whereas in controls, it varies with each parameter. Correlations with significance $>99 \%$ have been highlighted with ** and those with $>95 \%$ significance with * as shown in Tables 1-3.

\section{DISCUSSION}

The study that was done in this paper aimed at examining the effect of alendronate on the healing of acute distal radius fractures in 66 patients aged higher than 45 . It was concluded from this observational study that the administration of alendronate did not cause any adverse effects, as noted from radiological and clinical findings. There were found to be no significant differences in time of healing, QuickDASH score or any of the active wrist movements between patients who had been administered alendronate in comparison with those who were not on it when looking at statistical significances.

Bisphosphonates are effective therapeutic agents for an array of diseases related to the bone as they are good inhibitors of bone 
Table 2: Correlations between parameters for cases group

\begin{tabular}{|c|c|c|c|c|c|c|c|c|}
\hline Parameters & $\begin{array}{l}\text { QuickDASH } \\
\text { score }\end{array}$ & $\begin{array}{l}\text { Time of } \\
\text { healing } \\
\text { (weeks) }\end{array}$ & $\begin{array}{l}\text { Dorsi flexion } \\
(0-70)\end{array}$ & $\begin{array}{l}\text { Palmar } \\
\text { flexion } \\
(0-80)\end{array}$ & $\begin{array}{l}\text { Ulnar } \\
\text { deviation } \\
(0-35)\end{array}$ & $\begin{array}{l}\text { Radial } \\
\text { deviation } \\
(0-25)\end{array}$ & $\begin{array}{l}\text { Supination } \\
(0-80)\end{array}$ & $\begin{array}{l}\text { Pronation } \\
(0-70)\end{array}$ \\
\hline \multicolumn{9}{|l|}{ QuickDASH score } \\
\hline Pearson correlation & & -0.095 & $-0.895^{* *}$ & $-0.845^{* *}$ & $-0.798^{* *}$ & $-0.773^{* *}$ & $-0.847^{* *}$ & $-0.877^{* *}$ \\
\hline $\mathrm{p}$ & & 0.598 & 0.000 & 0.000 & 0.000 & 0.000 & 0.000 & 0.000 \\
\hline $\mathrm{N}$ & & 33 & 33 & 33 & 33 & 33 & 33 & 33 \\
\hline \multicolumn{9}{|l|}{ Time of healing (weeks) } \\
\hline $\mathrm{p}$ & & & 0.513 & 1.000 & 0.497 & 0.030 & 0.544 & 0.392 \\
\hline $\mathrm{N}$ & & & 33 & 33 & 33 & 33 & 33 & 33 \\
\hline \multicolumn{9}{|l|}{ Dorsi flexion (0-70) } \\
\hline Pearson correlation & $* *$ & & & $0.907^{* *}$ & $0.754^{* *}$ & $0.692^{* *}$ & $0.836^{* *}$ & $0.837^{* *}$ \\
\hline $\mathrm{p}$ & & & & 0.000 & 0.000 & 0.000 & 0.000 & 0.000 \\
\hline $\mathrm{N}$ & & & & 33 & 33 & 33 & 33 & 33 \\
\hline \multicolumn{9}{|l|}{ Palmar flexion (0-80) } \\
\hline Pearson correlation & $* *$ & & $* *$ & & $0.637^{* *}$ & $0.594^{* *}$ & $0.773^{* *}$ & $0.744^{* *}$ \\
\hline $\mathrm{N}$ & & & & & 33 & 33 & 33 & 33 \\
\hline \multicolumn{9}{|l|}{ Ulnar deviation (0-35) } \\
\hline Pearson correlation & $* *$ & & $* *$ & $* *$ & & $0.776^{* *}$ & $0.760^{* *}$ & $0.812^{* *}$ \\
\hline $\mathrm{p}$ & & & & & & 0.000 & 0.000 & 0.000 \\
\hline $\mathrm{N}$ & & & & & & 33 & 33 & 33 \\
\hline \multicolumn{9}{|l|}{ Radial deviation (0-25) } \\
\hline Pearson correlation & $* *$ & $*$ & $* *$ & $* *$ & $* *$ & & $0.707^{* *}$ & $0.809^{* *}$ \\
\hline $\mathrm{p}$ & & & & & & & 0.000 & 0.000 \\
\hline $\mathrm{N}$ & & & & & & & 33 & 33 \\
\hline \multicolumn{9}{|l|}{ Supination $(0-80)$} \\
\hline Pearson correlation & $* *$ & & $* *$ & $* *$ & $* *$ & $* *$ & & $0.928 * *$ \\
\hline $\mathrm{p}$ & & & & & & & & 0.000 \\
\hline $\mathrm{N}$ & & & & & & & & 33 \\
\hline \multicolumn{9}{|l|}{ Pronation $(0-70)$} \\
\hline Pearson correlation & $* *$ & & $* *$ & $* *$ & $* *$ & $* *$ & $* *$ & \\
\hline
\end{tabular}

${ }^{* *}$ Correlation is significant at the 0.01 level (two-tailed test). *Correlation is significant at the 0.05 level (two-tailed test). QuickDASH: Quick Disabilities of the Arm, Shoulder and Hand

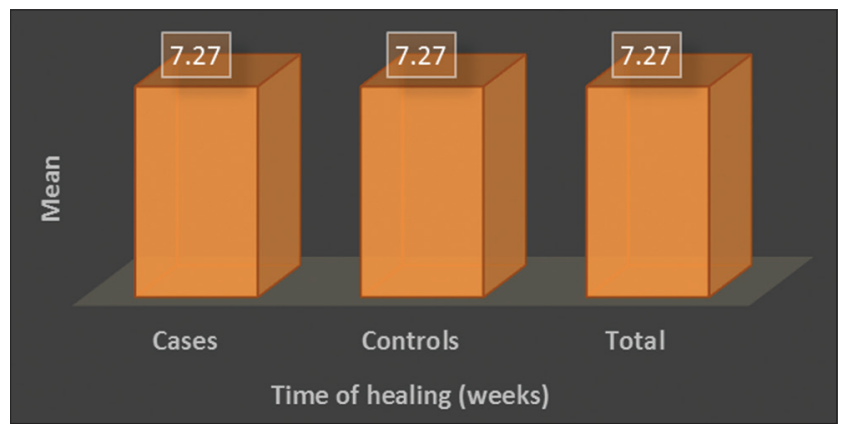

Graph 2: Mean of groups and total for time of healing (weeks)

resorption [7]. Due to their effectiveness in reducing the incidence of fragility structures, they are highly favored as therapeutic agents for osteoporosis [7]. They are categorized into nitrogen-containing and non-nitrogen-containing bisphosphonates based on their mechanism of action. Nitrogen-containing bisphosphonates have the property of persisting for a considerable amount of time on the surface of the bone. This has, in turn, resulted in an increased use of these agents in clinical practice through dosing intermittently [7]. Alendronate is a bisphosphonate which contains nitrogen which is administered orally and the above-stated reasons have led to it being given at a daily and weekly dosage of almost 7 times that of the standard daily dose [7]. It is estimated to have 10 years as its skeletal half-life, and thus, it is crucial to dissect the possible consequences of intake of this drug because of its intrinsic ability to suppress osteoclast function which affects the process of fracture repair [11]. This could result in patients not achieving full recovery of this function for quite a period. However, due to it being a low-cost bisphosphonate with a wide spectrum of fracture efficacy, it is considered in most of the cases as the first line of treatment [12]

Tripathy et al. [13] in their study determine the clinical profile and prescription pattern of drugs in the treatment of osteoporosis in a tertiary care center in Karnataka noted in their findings that alendronate was the most commonly prescribed bisphosphonate (55.56\%), prescribed as once weekly or once daily dose. Alendronate acts as a potent antiresorptive agent and inhibits farnesyl pyrophosphate synthase in osteoclasts, which need prenylated proteins for their function and survival [9]. As described in the paper by Uchiyama et al. [9] in 2013, the process of fracture healing is in the following order, though there exists some overlap between the stages: Inflammation, soft callus formation, hard callus formation, and hard callus remodeling. In the hard callus remodeling stage, osteoclasts are very much active. Alendronate is not seen to affect directly osteoblasts or other cells which participate in any of the first three stages mentioned above. Therefore, it can be inferred that callus formation radiologically, may not be affected by alendronate in a substantial manner; however, delays in remodeling of the hard callus could occur, as are also indicated in various animal studies. The process of bone remodeling goes hand in hand with other processes such as cartilage mineralization, vascular invasion as well as formation of the woven bone. Furthermore, osteoclasts are seen to be active from the beginning stages of fracture healing, removing necrotic bone from the fracture site. Hence, there always exists a possibility of delay in fracture healing occurring as a result of osteoclast dysfunction when administration of alendronate is started immediately.

Uchiyama et al., in 2013, [9] concluded from their study that administration of alendronate, early on after an operatively treated distal radius fracture did not seem to delay the healing of the fracture either radiologically or clinically, from their analysis of 80 patients overall with 
Table 3: Correlations between parameters for controls group

\begin{tabular}{|c|c|c|c|c|c|c|c|c|}
\hline Parameters & $\begin{array}{l}\text { QuickDASH } \\
\text { score }\end{array}$ & $\begin{array}{l}\text { Time of } \\
\text { healing } \\
\text { (weeks) }\end{array}$ & $\begin{array}{l}\text { Dorsi } \\
\text { flexion } \\
(0-70)\end{array}$ & $\begin{array}{l}\text { Palmar } \\
\text { flexion } \\
(0-80)\end{array}$ & $\begin{array}{l}\text { Ulnar } \\
\text { deviation } \\
(0-35)\end{array}$ & $\begin{array}{l}\text { Radial } \\
\text { deviation } \\
(0-25)\end{array}$ & $\begin{array}{l}\text { Supination } \\
(0-80)\end{array}$ & $\begin{array}{l}\text { Pronation } \\
(0-70)\end{array}$ \\
\hline \multicolumn{9}{|l|}{ QuickDASH score } \\
\hline Pearson correlation & & -0.031 & $-0.735^{* *}$ & $-0.645^{* *}$ & $-0.586^{* *}$ & $-0.733^{* *}$ & $-0.715^{* *}$ & $-0.726^{* *}$ \\
\hline $\mathrm{p}$ & & 0.864 & 0.000 & 0.000 & 0.000 & 0.000 & 0.000 & 0.000 \\
\hline $\mathrm{N}$ & & 33 & 33 & 33 & 33 & 33 & 33 & 33 \\
\hline \multicolumn{9}{|l|}{ Time of healing (weeks) } \\
\hline $\mathrm{p}$ & & & 0.906 & 0.940 & 0.446 & 0.939 & 0.455 & 0.402 \\
\hline $\mathrm{N}$ & & & 33 & 33 & 33 & 33 & 33 & 33 \\
\hline \multicolumn{9}{|l|}{ Dorsi flexion (0-70) } \\
\hline Pearson correlation & $* *$ & & & $0.872 * *$ & $0.579 * *$ & $0.598 * *$ & $0.744^{* *}$ & $0.832 * *$ \\
\hline $\mathrm{p}$ & & & & 0.000 & 0.000 & 0.000 & 0.000 & 0.000 \\
\hline $\mathrm{N}$ & & & & 33 & 33 & 33 & 33 & 33 \\
\hline \multicolumn{9}{|l|}{ Palmar flexion $(0-80)$} \\
\hline Pearson correlation & $* *$ & & $* *$ & & $0.573^{* *}$ & $0.612^{* *}$ & $0.827^{* *}$ & $0.861^{* *}$ \\
\hline $\mathrm{N}$ & & & & & 33 & 33 & 33 & 33 \\
\hline \multicolumn{9}{|l|}{ Ulnar deviation (0-35) } \\
\hline Pearson correlation & $* *$ & & $* *$ & $* *$ & & $0.734^{* *}$ & $0.593^{* *}$ & $0.630^{* *}$ \\
\hline $\mathrm{p}$ & & & & & & 0.000 & 0.000 & 0.000 \\
\hline $\mathrm{N}$ & & & & & & 33 & 33 & 33 \\
\hline \multicolumn{9}{|l|}{ Radial deviation (0-25) } \\
\hline Pearson correlation & $* *$ & & $* *$ & $* *$ & $* *$ & & $0.594^{* *}$ & $0.674^{* *}$ \\
\hline $\mathrm{p}$ & & & & & & & 0.000 & 0.000 \\
\hline $\mathrm{N}$ & & & & & & & 33 & 33 \\
\hline \multicolumn{9}{|l|}{ Supination (0-80) } \\
\hline Pearson correlation & $* *$ & & $* *$ & $* *$ & $* *$ & $* *$ & & $0.895^{* *}$ \\
\hline $\mathrm{p}$ & & & & & & & & 0.000 \\
\hline $\mathrm{N}$ & & & & & & & & 33 \\
\hline \multicolumn{9}{|l|}{ Pronation (0-70) } \\
\hline Pearson correlation & $* *$ & & $* *$ & $* *$ & $* *$ & $* *$ & $* *$ & \\
\hline
\end{tabular}

${ }^{* *}$ Correlation is significant at the 0.01 level (two-tailed test). QuickDASH: Quick Disabilities of the Arm, Shoulder and Hand

40 being administered alendronate and 40 , not being administered the drug. A double-blind study, in 2000, conducted by Van Der Poest Clement et al. [14] to examine how bone loss after a fracture in women having Colles' fracture and postmenopausal osteoporosis is affected by alendronate; a $10 \mathrm{mg}$ dosage of the drug or placebo was administered to 37 women who were diagnosed with distal forearm fracture and low bone mineral density (BMD) of the lumbar spine. Heightened levels of resorption combined with decreased formation resulted in bone loss after a fracture occurrence and in the immobilization period. Hike in the BMD of the hip and lumbar spine, as well as decrease in nonspine fracture incidence in postmenopausal women with osteoporosis, was seen to occur as a result of alendronate. A study conducted by Rozental et al. [15], in 2009, looked into a comparison of healing rates of distal radius fractures in patients who were on bisphosphonate therapy at the injury time with those who were not on it. A total of 196 patients were considered out of which the patients who were on the therapy were 43 and those who were not, made up the control group with 153 patients. The factors which affected time to radiographic union were assessed using regression analysis and it was discovered that the average time to union was a bit lengthier in patients who were on bisphosphonate as opposed to those who were not it, with a ratio of 55 to 49 days. Thus, an increased time of healing was noted with bisphosphonate use, but that was deemed not satisfactory enough to demonstrate a clinical significance. Gong et al. [16] conducted a study in 2012 to determine the effect of early administration of bisphosphonate on the healing of osteoporotic distal radius fractures. This study focused on a randomized clinical trial to determine how safe it is for a patient who has an acute distal radius fracture to be administered bisphosphonates. It was inferred that osteoporotic medication after stable fracture fixation can be started early on in patients who faced a possible risk of future fracture. In their study to evaluate the effectiveness of certain bisphosphonates for the treatment of osteoporosis in postmenopausal women over the age of 50 in Tirana, Miraçi et al. [17] considered both alendronate as well as ibandronate.
Although the beneficial reasons for bisphosphonates may be justified from the improvements seen in patients, it is necessary to put in a word about the possible consequences of their usage. Bisphosphonates suppress the process of bone resorption by inhibiting osteoclast formation, which could in turn cause changes in remodeling, bone mineral content as well as affect the tensile strength of the healing bone [18]. In addition, a preferential deposition of oral and intravenous bisphosphonates at the site of an acute fracture has been noticed in many cases, and this could significantly affect clinical healing of these fractures [18]. Case studies performed by Odvina et al. [6], Goh et al. [19], and Kwek et al. [20] which looked into sets of atypical nonspine fractures of patients who have been on bisphosphonate therapy for a long period of time raised concerns about its usage. It was observed that fracture healing was delayed or absent for 3 months up to 2 years for a significant number of these patients while they were on therapy. Atypical femoral fractures and osteonecrosis of the jaw are some of the consequences of the use of bisphosphonates on a long duration basis, and thus, the exact duration of administration has been a topic of dispute in the field of orthopedics [12]. It was seen that inhibition of the hard callus remodeling to mature lamella bone occurs as a result of bisphosphonate use in several animal studies which have been conducted $[7,8]$. While the risk of using bisphosphonates has been found to be statistically significant in many of these studies, it is a worthy point that the clinical significance is still unclear. Bisphosphonates are seen to be highly beneficial in decreasing fracture risk and it is a fact that the anguish and fatality associated with a new fracture occurrence is higher than that of nonunions which have been seen [15]. Hence, a proper evaluation of when to start the treatment following a fracture requires in-depth analysis as a delayed start must not result in initiation issues with these agents.

There are several limitations to this study which include the following points: Difficulty in finding out whether the patient has shown compliance in administration of the drug, limited number of subjects resulting in data compilation which may not be exactly accurate in a 
real situation and inter observer variability in assessment of fracture healing.

\section{CONCLUSION}

It was observed that alendronate administration in distal radius fractures did not seem to delay fracture healing times either radiologically or clinically.

\section{REFERENCES}

1. Hagino $H$, Yamamoto $K$, Ohshiro $H$, Nakamura $T$, Kishimoto $H$, Nose T. Changing incidence of hip, distal radius, and proximal humerus fractures in Tottori Prefecture, Japan. Bone 1999;24(3):265-70.

2. Court-Brown CM, Caesar B. Epidemiology of adult fractures: A review. Injury 2006;37(8):691-7.

3. Sontag A, Krege JH. First fractures among postmenopausal women with osteoporosis. J Bone Miner Metab 2010;28(4):485-8

4. Little EA, Eccles MP. A systematic review of the effectiveness of interventions to improve post-fracture investigation and management of patients at risk of osteoporosis. Implement Sci 2010;5:80

5. Eriksen EF, Lyles KW, Colón-Emeric CS, Pieper CF, Magaziner JS, Adachi JD, et al. Antifracture efficacy and reduction of mortality in relation to timing of the first dose of zoledronic acid after hip fracture. J Bone Miner Res 2009;24(7):1308-3.

6. Odvina CV, Zerwekh JE, Rao DS, Maalouf N, Gottschalk FA, Pak CY. Severely suppressed bone turnover: A potential complication of alendronate therapy. J Clin Endocrinol Metab 2005;90(3):1294-301.

7. Manabe T, Mori S, Mashiba T, Kaji Y, Iwata K, Komatsubara S, et al. Effect of dosing interval duration of intermittent ibandronate treatment on the healing process of femoral osteotomy in a rat fracture model. Calcif Tissue Int 2012;90(3):193-201

8. Amanat N, McDonald M, Godfrey C, Bilston L, Little D. Optimal timing of a single dose of zoledronic acid to increase strength in rat fracture repair. J Bone Miner Res 2007;22(6):867-76.

9. Uchiyama S, Itsubo T, Nakamura K, Fujinaga Y, Sato N, Imaeda T, et al. Effect of early administration of alendronate after surgery for distal radial fragility fracture on radiological fracture healing time. Bone Joint
J 2013;95-B(11):1544-50.

10. Thompson JC. Netter's Concise Orthopaedic Anatomy. $2^{\text {nd }}$ ed. Philadelphia: Saunders, Elsevier; 2010

11. Wu F, Mason B, Horne A, Ames R, Clearwater J, Liu M, et al. Fractures between the ages of 20 and 50 years increase women's risk of subsequent fractures. Arch Intern Med 2002;162(1):33-6.

12. Compston J, Bowring C, Cooper A, Cooper C, Davies C, Francis R, et al. Diagnosis and management of osteoporosis in postmenopausal women and older men in the UK: National Osteoporosis Guideline Group (NOGG) update 2013. Maturitas 2013;75(4):392-6.

13. Tripathy A, Adiga S, Shah HH, Shahbhag TV, Kumar DM. A retrospective study of clinical profile and drug prescribing pattern in osteoporosis in a tertiary care hospital. Int $\mathrm{J}$ Pharm Pharm Sci 2015;7(10):390-3.

14. van der Poest Clement E, Patka P, Vandormael K, Haarman H, Lips P. The effect of alendronate on bone mass after distal forearm fracture. J Bone Miner Res 2000;15(3):586-93.

15. Rozental TD, Vazquez MA, Chacko AT, Ayogu N, Bouxsein ML. Comparison of radiographic fracture healing in the distal radius for patients on and off bisphosphonate therapy. J Hand Surg Am 2009;34(4):595-602.

16. Gong HS, Song CH, Lee YH, Rhee SH, Lee HJ, Baek GH. Early initiation of bisphosphonate does not affect healing and outcomes of volar plate fixation of osteoporotic distal radial fractures. J Bone Joint Surg Am 2012;94(19):1729-36.

17. Miraçi M, Demeti A, Ylli Z, Kelliçi S, Tarifa D. The cost-effectiveness of ibandronate and alendronate for the treatment of osteoporosis in a specialized clinic in Tirana. Int J Pharm Pharm Sci 2015;7(10):207-11.

18. Kristiansen TK, Ryaby JP, McCabe J, Frey JJ, Roe LR. Accelerated healing of distal radial fractures with the use of specific, low-intensity ultrasound. A multicenter, prospective, randomized, double-blind, placebo-controlled study. J Bone Joint Surg Am 1997;79(7):961-73.

19. Goh SK, Yang KY, Koh JS, Wong MK, Chua SY, Chua DT, et al. Sub trochanteric insufficiency fractures in patients on alendronate therapy: A caution. J Bone Joint Surg Br 2007;89(3):349-53

20. Kwek EB, Goh SK, Koh JS, Png MA, Howe TS. An emerging pattern of sub trochanteric stress fractures: A long-term complication of alendronate therapy? Injury 2008;39(2):224-31 